\title{
Building security in the arctic region of eastern Siberia
}

\author{
Sergei Amelchugov ${ }^{1 *}$, Oksana Gofman ${ }^{1}$, Oksana $S$ Mitskevich $^{1}$, Elena Danilovich ${ }^{1}$ \\ ${ }^{1}$ Siberian Federal University, School of Engineering and Construction, 660041, Pr. Svobodny 82, \\ Russia
}

\begin{abstract}
The article considered the process of global warming, which is mostly represented in the northern territories of Eastern Siberia. A growth of snowfall gradient and wind load gradient, resulting in building up of snowy thermal insulation layer, which prevents ground freezing, is analyzed. According to the preliminary calculations the forecast of thawing of the permafrost will completely degrade in the second part of the $21^{\text {st }}$ century.

The increase of the temperature and the strength of the active layer lead to the building and structures deformation. Together with natural factors technogenic and anthropogenic factors have a great impact: effect from building operation, improper handling of pile-foundation (restricted ventilation of crawlway, no provided runoff), destruction of networks. The simulation model of climate fluctuation influence on thawing of the permafrost was developed. The melting process or correspondingly crystallization takes place during thawing/freezing of the permafrost.
\end{abstract}

The process of global warming is most pronounced in the northern territories of Eastern Siberia; the observed trend is on average $0.6^{\circ} \mathrm{C}$ over 10 years [1]. This is reflected in the strengthening of wind and snow loads on buildings and structures, significantly different from the standard values presented in Fig. 1.
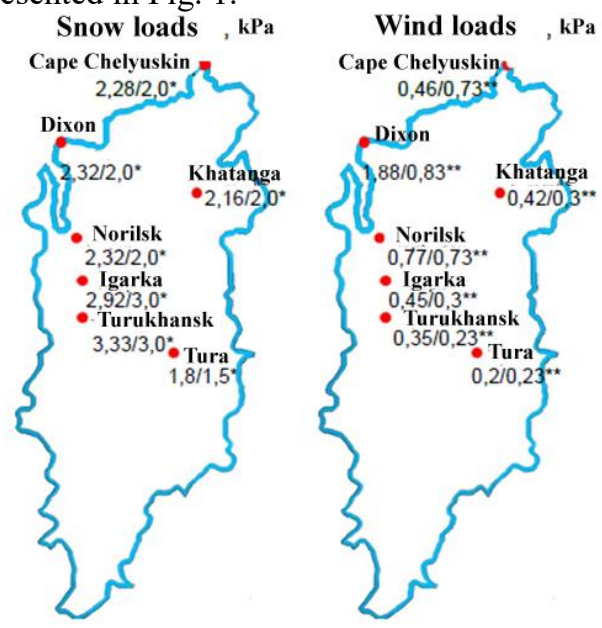

${ }^{*}$ Corresponding author: asp-911@yandex.ru 
Fig. 1. Changes in snow and wind loads. Values * and ** are adopted in accordance with SP 131.13330-2011 «Construction climatology».

The increase in the gradient of snow precipitation leads to the formation of a snow thermal insulating layer, which prevents the freezing of the soil. Fig. 2 shows multimeter accumulations of snow in the inner courtyards of urban areas.

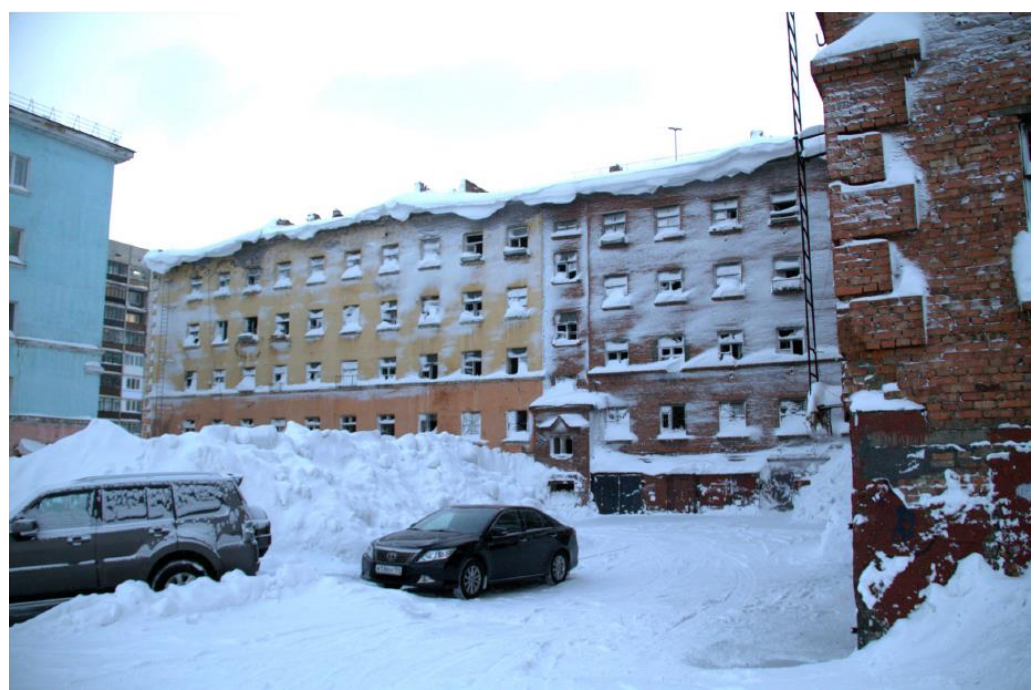

Fig. 2. Snowdrifts in courtyards.

The ambient temperature change is most pronounced in the winter period (see fig. 3).

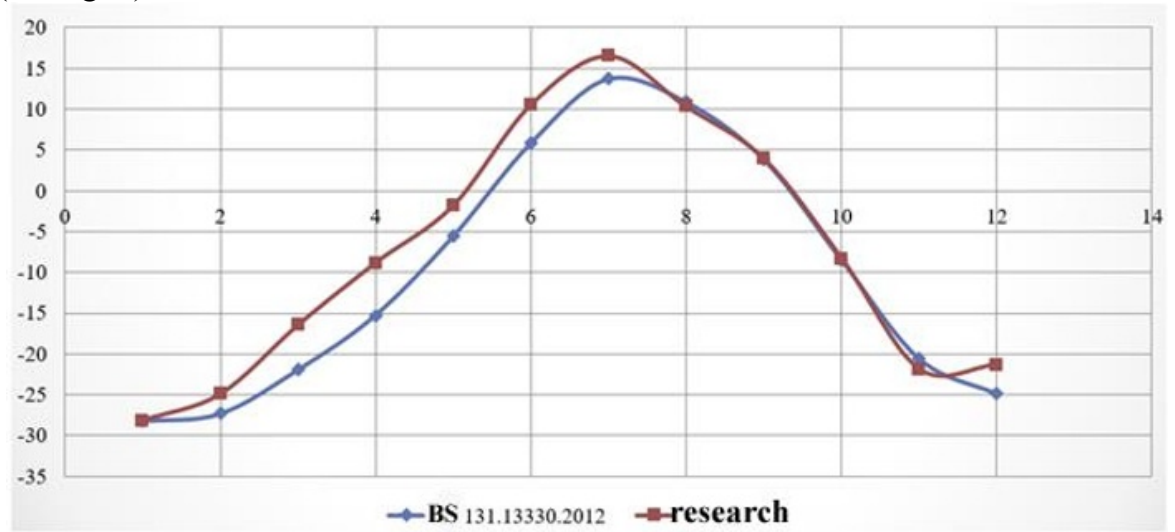

Fig. 3. The change in air temperature in Norilsk

Climate change forecast according to A1B scenario assumes surface warming of the territory of Eastern Siberia by the end of this century, higher than 7.5 degrees Celsius [3]. 


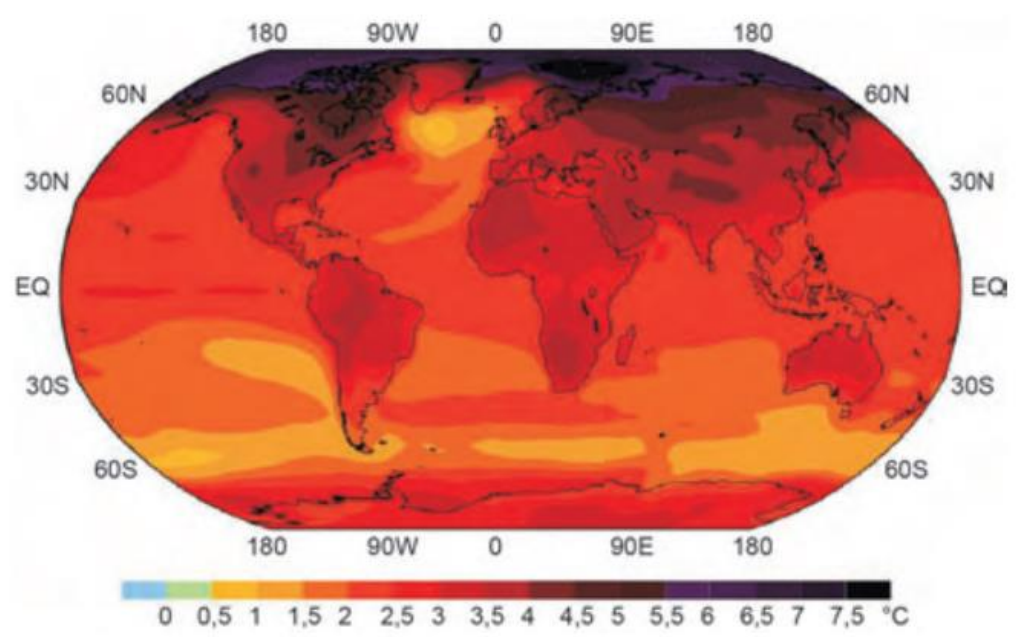

Fig. 4. Global climate change. Geographical distribution of warming at the end of the XXI century.

According to modern research, the soil temperatures at a depth of $10-15$ meters can be + $4+6^{\circ} \mathrm{C}$ and differ from those established in the $70-80$ s by $6-10^{\circ} \mathrm{C}$. Calculation of the forecast of the permafrost is presented in Picture 5. According to preliminary calculations, in the second half of the 21 st century the permafrost layer completely degrades.

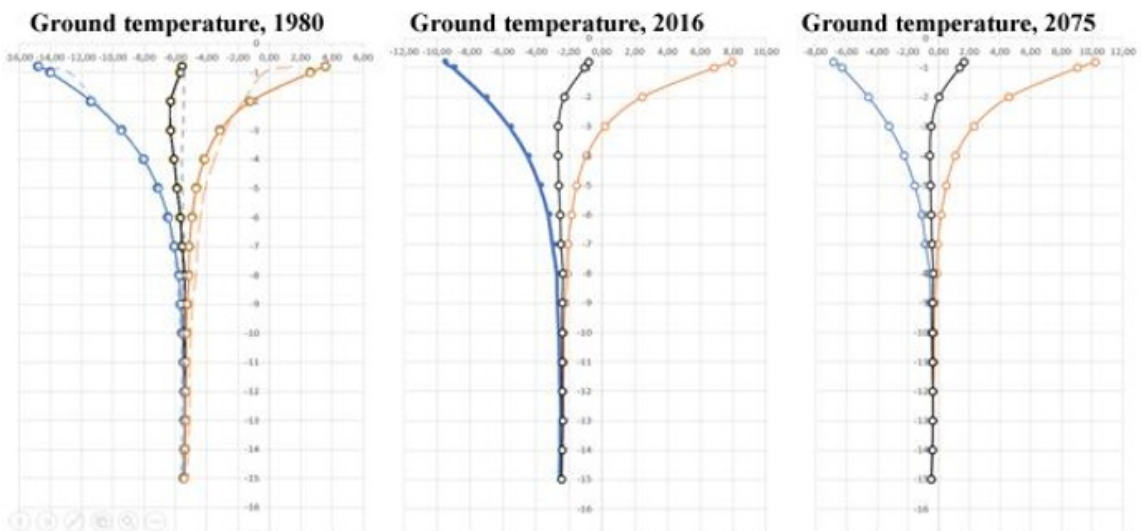

Fig. 5. Thawing of permafrost.

Temperature increase of the active layer and an increase in its capacity lead to deformations of the basements of buildings and structures. In addition to natural factors, technogenic and anthropogenic factors have a great influence: impacts from the operation of buildings and structures, violation of the rules for the operation of pile foundations (restriction of ventilation of technical subfloors, lack of organized runoff), destruction of networks.

The most critical situation with cryogenic destruction of buildings is in the city of Norilsk. In recent years, 120 multistory buildings have been demolished (about $10 \%$ of the city housing stock). Out of 859 existing apartment buildings in the city of Norilsk, currently more than $30 \%$ are in critical condition (Pictures 6 and 7). 


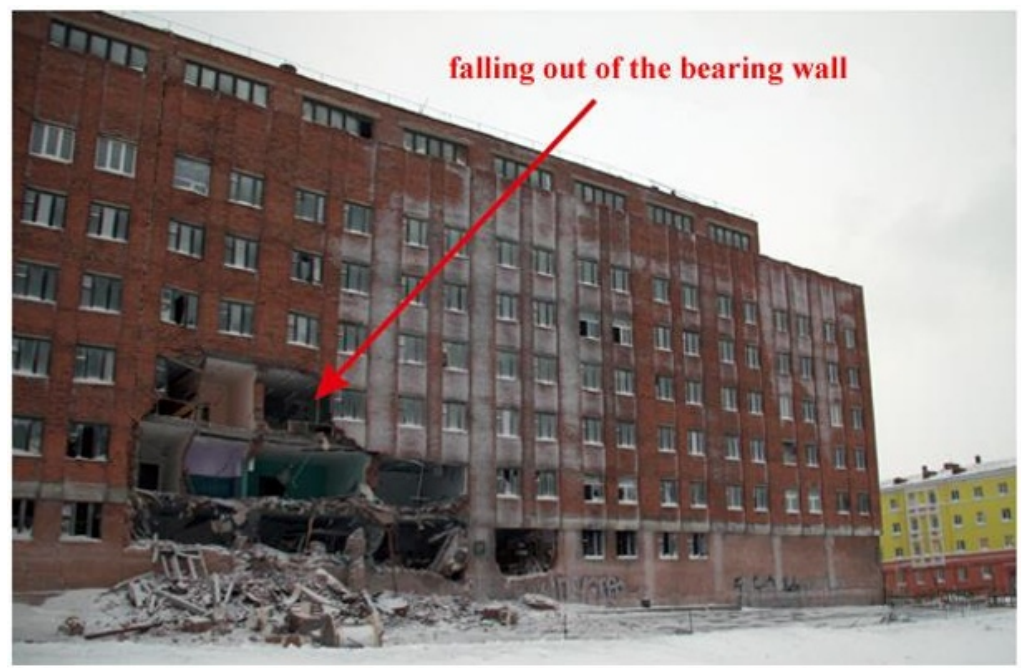

Fig. 6. Destruction of administrative buildings in the city of Norilsk

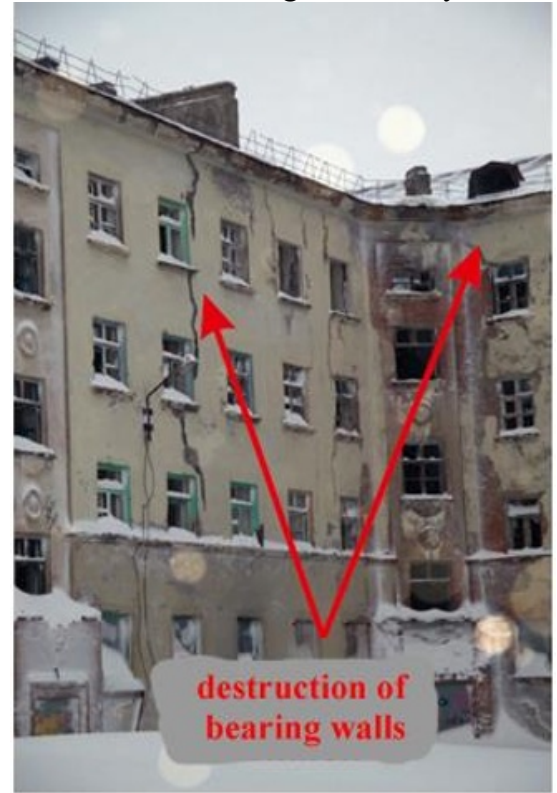

Fig. 7. Destruction of residential buildings in the city of Norilsk

The main design solution for the foundations of buildings and structures are combined piles: the bottom of the pile is made of monolithic concrete; upper part - prefabricated reinforced concrete docked piles [2].

A model to calculate the effect of climate change on the permafrost thawing was constructed. While thawing / freezing of permafrost soils, the process of melting or crystallization occurs. In this work, the formulation of enthalpy - porosity is used to model these processes. In this method, the melt boundary is not tracked explicitly. Instead, a quantity called the volume fraction of the liquid fraction, which indicates the proportion of the volume of cells in a liquid state, is entered. The liquid fraction is calculated at each iteration, based on the enthalpy balance. In the two-phase zone, the liquid fraction has a value from 0 to 1 . It is modeled as a "pseudo" porous environment in which the porosity decreases from 1 to 0 , which indicates solidification of the material. When the material solidifies completely in the 
cell, the porosity becomes zero and, consequently, the speed also drops to zero. The twophase liquid-solid zone is considered as a porous zone with porosity equal to the volume part of the liquid fraction. The graphical interpretation of the process is presented in Picture 8 . The corresponding sources of the flow (inflow) of energy and impulse are added to the conservation of energy and the conservation of impulse. For solidification / melting tasks, the energy equation is written as:

$$
\frac{\partial}{\partial t}(\rho H)+\nabla(\rho \vec{u} H)=\nabla(k \nabla T),
$$

where: $H$ - enthalpy; ${ }^{\rho}$ - thickness; $\vec{v}$ - fluid speed.

The enthalpy-porosity approach models the two-phase area (partially solidified area) as a porous environment. The porosity in each cell is set equal to the fraction of the liquid phase in that cell. In fully hardened materials, the porosity is zero. The drain of the pulse due to the decrease in porosity in the two-phase zone looks as follows:

$$
S=\frac{(1-\beta)^{2}}{\left(\beta^{3}+\varepsilon\right)} A_{m u s h}(\vec{v}),
$$

where: ${ }^{\beta}$-volume of liquid phase; ${ }^{\varepsilon}$ - numerical parameter $(0.001)$ to prevent division by zero; $A_{m u s h}$-two-phase region constant;
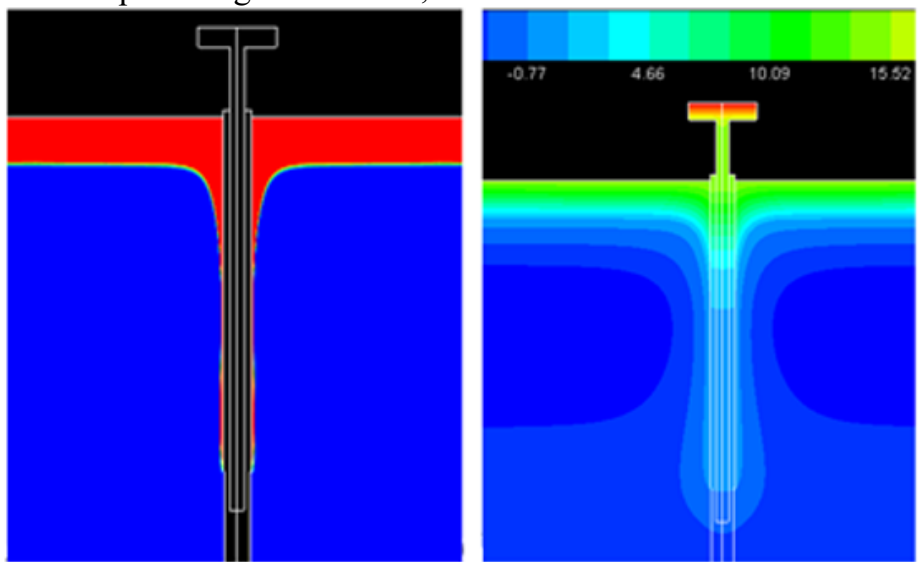

Fig. 8. The calculated values of the temperature distribution (a) and the distribution of the liquid phase around the pile (b) for August in Norilsk.

The important practical issue in the calculation of pile foundations of structures in soils with complex rheological properties is the development of a reliable model for calculating the interaction of pile foundations with thawed soils when exposed from quasi-static forces of the own structure weight. This interaction is largely determined by the behavior of the "pile-soil" system. The complexity of analyzing the quasi-static behavior of this system consists of: the heterogeneity of the pronounced rheological features of the melted ground; nonlinear nature of the interaction of the pile with the soil at the interface. The construction of the mathematical model was carried out within the framework of the mechanics of a deformable solid [5]. Accounting for the rheological features of soils is carried out under the assumption that the soil as a deformable body exhibits elastic, viscoelastic and plastic features. It is also assumed that according to these features the soil has the heterogeneous consistency. The description of these features is carried out within the framework of the linear hereditary viscoelasticity and the theory of small viscoplastic deformations, according to the deformation theory of U.A. Ilyushin. Taking into account the assumptions made above, the determining (physical) ratios for the soil will be: 


$$
\begin{gathered}
\varepsilon(x, t)=e(x, t)+\frac{\Theta(x, t)}{3} E \\
\sigma(x, t)=S(x, t)+\frac{\sigma_{a v g}(x, t)}{3} E \\
S(x, t)=2 G\left\{e(x, t)-\omega(\gamma) e(x, t)-\int_{0}^{t} R(t-\tau)[e(x, t)-\omega(\gamma) e(x, t)] d \tau\right\} \\
\sigma(x, t)=3 B\left\{\Theta(x, t)-g(\gamma) \Theta(x, t)-\int_{0}^{t} \Pi(t-\tau)[\Theta(x, t)-g(\gamma) \Theta(x, t)] d \tau\right\}
\end{gathered}
$$

Where: $\quad \varepsilon(x, t)$ - deformation tensor, $e^{e(x, t)}$ - deformation tensor deviator, $\sigma(x, t)$ - voltage tensor, $S(x, t)$ - voltage tensor deviator, $\omega(\gamma), g(\gamma)$ - scalar plasticity functions, $R(t-\tau), \quad \Pi(t-\tau)$ - relaxation functions, $G, \quad B \quad$ - fixed material values, $\gamma=2 \sqrt{-e_{11} e_{22}+e_{12}^{2}-e_{22} e_{33}+e_{23}^{2}-e_{11} e_{33}+e_{31}^{2}}, \Theta=\varepsilon_{11}+\varepsilon_{22}+\varepsilon_{33}$.

The description of the interaction of the pile with the soil at the boundary of their contact was carried out using the Coulomb friction law. It is assumed that the pile during deformation shows only elastic features. For the numerical implementation of the obtained boundary value problem, the variational principle of possible displacements is used. Numerical solutions of this problem allow: to estimate the bearing capacity of the pile; determine the evolution of pile displacement; to compare the significance of the viscoelastoplastic features of the soil and the possibility of the influence of slipping on the evolution of the pile displacement; use the resulting solutions to identify the physicomechanical properties of the soil when compared with the results of experimental field test data. Parametric studies have shown that in the junction of monolithic and precast reinforced concrete piles, the soils change their mechanical features. This causes uneven precipitation of the subsoil and deformation of the pile.

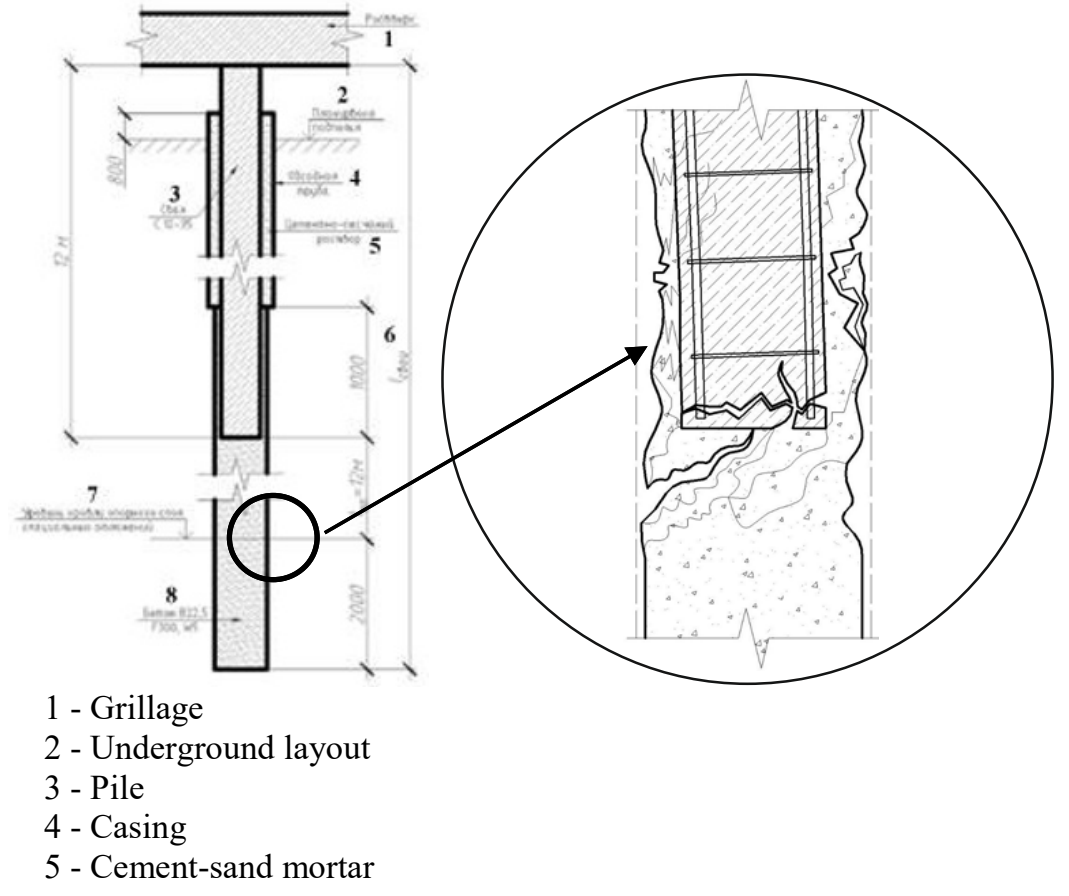


6 - Piles

7 - Level of roof of the supporting layer of glacial deposits

8 Concrete

Fig. 9. The nature of the destruction of a typical composite pile

The characteristic of the water regime in the Arctic territories of Eastern Siberia is almost completely absent; therefore, ensuring the safety and sustainability of buildings based on the conditions of the water-thermal regime is not possible.

Thus, at present, for buildings and structures of the Arctic zone of Eastern Siberia. the following issues are specific

1. Research issue

The variegated ground conditions of the Arctic zone of Eastern Siberia require detailed geological, geocryogenic and hydrogeological studies. According to modern surveys, the temperature of the soil at a depth of $10-15$ meters differs from minus 10 to plus $6^{\circ} \mathrm{C}$. In the calculations of the mechanical features of soils, the nonlinearity of the phase transition of water in soils and the transition of soils into plastic deformations are not taken into account. Global warming and changes in wind and snow loads can make significant adjustments to the prediction of the state of the permafrost.

2. Design and construction issue

The adopted standard decision on precast pile foundations for mass construction of the cities of Norilsk, Dudinka and others in the region due to complex geological conditions is incorrect. There is no forecast of the behavior of various foundation structures on thawing permafrost. There is no reliable information about the effectiveness of freezing and / or maintaining frozen soils under buildings. Each construction site should have its own decisions based on detailed and as complete survey as possible. What is more, there is only a limited use of high-quality building structures and materials; information on hydrological research is needed.

\section{Construction issue}

Small summer period; the lack of a sufficient amount of construction machinery, equipment, mechanisms; a large number of days in which the construction is not limited by weather conditions; poor quality mixes and materials.

\section{Operation issue}

Non-compliance with the rules of operation led to additional changes in the ground conditions within the boundaries of the building. Restriction of ventilation, unorganized drainage of storm water, damaged networks - all these factors lead to a decrease in the mechanical features of the soil not only within the active layer, but also below the permafrost boundary.

\section{Utilization issue}

Construction involves the use of ventilated subfields of buildings for the construction of trunk networks and communications, so the complete demolition of buildings is limited. Remaining pile fields and foundation grills are not recyclable.

\section{Conclusions}

- $\quad$ Refusal of standard design. Designing objects must be tied to a specific site. Under good conditions, high-rise construction is allowed; under difficult conditions, the building should be limited to loads and heights.

Development of geotechnical, geocryogenic and geohydrological monitoring systems, as well as the monitoring of the condition of the supporting structures of buildings; development of methods for predicting the deformations of existing buildings. The implementation of on-line collection and transmission of information about the state of the building structures and its engineering networks; cease of the ingress of snow and water under the 
buildings, storm water removal systems, as well as the additional drainage and thermal stabilization of the building foundations.

Development of design solutions for the use of deformed foundations as the basis for new construction; calculation of the actual bearing capacity; implementation of monitoring systems from the zero cycle stage; decrease in loadings due to use of wooden construction.

\section{References}

1. Technical report No. 349493 on engineering-geological researches. LKiZ of Norilskproyekt institute.

2. The report on features of climate in the territory of the Russian Federation for 2016. Moscow, 70 (2017)

3. Assessment of macroeconomic consequences of climate change in the territory of the Russian Federation until 2030 and further prospect. Moscow, 254 (2011)

4. The report on features of climate in the territory of the Russian Federation for 2016. Moscow, 70 (2017)

5. CP 25.13330.2012 Bases and the bases on permafrost soil. Staticized edition SNiP 2.02.04-88. - Vved. 2013-01-01, Moscow: OAOTsPP, 236 (2012)

6. Gryza G.V., Rankova E. Ya. The observed and expected climate changes of Russia: air temperature. - M.: Publishing house of federal state budgetary Institution «VNIIGMIMTsD, 195 (2012)

7. Grekhnev N.I., Lipina L. N., Lapekina S.I. Mountain information and analytical bulletin, 220 (2014)

8. Provisional WMO Statement on the Status of the Global Climate in 2016, WMO Press Release, 15, 14 November 2016

9. IPCC, 2013: Climate Change 2013: The Physical Science Basis. Contribution of Working Group I to the Fifth Assessment Report of the Intergovernmental Panel on Climate Change. Cambridge University Press, Cambridge, United Kingdom and New York, NY, USA, 1535, 19, 764 (2006)

10. Jafarov, E.E. The Cryosphere, Author(s), 662, (2012)

11. Karl T.R., A. Arguez, B. Huang, J.H. Lawrimore, J.R. McMahon, M.J. Menne, T.C. Peterson, R.S. Vose, and Huai-Min Zhang, 2015: Science 26 June 2015: 1469-1472

12. Nicolsky, D.J. Cold Regions Science and Technology, 10, (2008)

13. Bartolomei A.A., Omel'chak I.M., Soil Mechanics and Foundation Engineering, 5, 153 160 (2003)

14. JMA, 2014: Climate Change Monitoring Report. 1-3-4 Otemachi, Chiyodaku, Tokyo 100-8122, Japan

15. Bell S. W. and Geller M. A. J. Geophys. Res., 2008, vol. 113, DOI: 10.1029/2077JD009022

16. Berthet G., Esler J. G., and Haynes P. H. A J. Geophys. Res.,, vol. 112, DOI: 10.1029/2006JD008295 (2007+

17. IPCC 2007. The Physical Science Basis. Contribution of Working Group I to the Fourth Assessment Report. - Cambridge, Cambridge University Press, (2007)

18. Leffingwell E. Ground ice-wedges, the dominant form of ground-ice on the North Coast of Alaska, J. Geol., 1915, 23, 654

19. Neller et al. J. Geophys. Res., 1996, vol. 101, D3, 1387-1399

20. Stratospheric Processes and Their Role in Climate SPARC, A Project of the WMO/ICSULIOC Wold Climate Research Programme SPARC Intercomparison of Middle Atmosphere Climatologies, December 2002. -Geneva, WMO, 109, (2002)

21. Konakhina, N.A. IOP Conf. Ser. Earth Environ. Sci, 180 (1), 012018: (2018) 
22. Kikkas, K., Romashkina, E.Potential IOP Conference Series: Earth and Environmental Science, 180 (1), 012016: (2018)

23. Kozmenko, S., Teslya, A., Fedoseev, S. IOP Conf. Ser. Earth Environ. Sci 180 (1), 012009: (2018)

24. Glukhov, V.V., Tukkel, I.L., Detter, G.F. IOP Conf. Ser. Earth Environ. Sci 180 (1), 012003 (2018) 